\title{
RWOPS - light at the end of a dusty tunnel
}

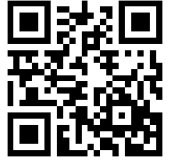

The government will hold hospital line managers responsible for ensuring that consultants and doctors deliver at least 56 hours of State work per week - if they are to do any Remunerated Work Outside the Public Service (RWOPS) at all. This will be nationally legislated, Izindaba has learnt.

This emerged from Dr Deon Menge, the South African Medical Association (SAMA)'s 'point man' for RWOPS and a key member of the national RWOPS committee advising Dr Aaron Motsoaledi, the National Minister of Health. The committee consists of Dr Terence Carter, Deputy Director-General: Hospitals Tertiary Service and Workforce Management, Prof. Errol Holland, Chair of the South African Committee of Medical Deans, Prof. Gert van Zyl, Dean of the Faculty of Health Sciences at the University of the Free State, his Cape Town counterpart, Prof. Wim de Villiers, and Dr Poppy Ramathuba, Chairperson of SAMA's Public Sector Committee.

Menge, a general surgeon at Pelonomi Hospital in Bloemfontein, said the biggest change to the easily and widely abused current setup will be a standardised protocol across provinces with line managers being held directly responsible for ensuring consultants work their minimum 56 hours per week (40 hours plus 16 hours of paid overtime). Earlier this year, Izindaba foreshadowed and documented several dramatic blowups between consultants on one side and hospital managers and provincial and national politicians on the other, complete with resignations, official threats and nearslanderous accusations. ${ }^{[1,2]}$ A cloud still hangs over scores of consultants under investigation in various provinces for neglecting public patients in favour of lucrative private work. KwaZulu-Natal is even probing the feasibility of proving whether the absence of some consultants from State hospital bedsides can be linked to actual adverse patient outcomes, which have historically cost the province hundreds of millions of rands in civil claims. ${ }^{[2]}$

\section{Final details being ironed out}

Menge said the RWOPS advisory committee planned to have a final meeting before the end of the year to 'iron out the finer details', which would then go to Motsoaledi, who

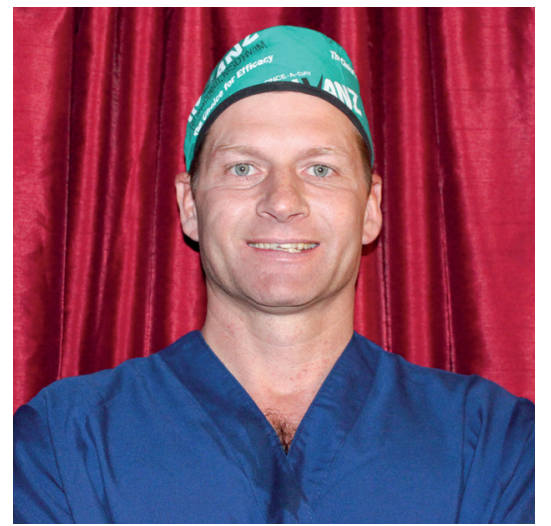

Dr Deon Menge, SAMA's RWOPS representative.

would table it in Parliament as a white paper for final enactment, a process that could take up to two years or more. He explained that for each doctor the line manager would be different, depending on his/her specialty or designated work. 'The State hours can still be flexi-time, not a rigid insistence that you're "on station" from 8 am to 4 pm every day but you need to do your 56 hours over that week. The biggest change is that government will hold the line manager responsible to make sure you do your hours. They pay him to manage and the RWOPS will have to be in accordance with him, he said. Izindaba discovered that not only was RWOPS (as practised by some) causing dissention and fall-out among doctors themselves (with already hard-pressed junior staff left to do the work), but some line managers are reluctant to confront long-serving senior colleagues, effectively 'turning a blind-eye' and resulting in abusive RWOPS practice becoming close to the norm in several State hospitals.

\section{Ethical 'white-anting' of juniors}

Leading medical ethicists and doctors at the centre of reforming the healthcare system in advance of universal health coverage spoke out strongly against the abuse, pointing to the 'moral white-anting' of younger doctors entering the State service as they witnessed widespread subtle or blatant neglect of State patients in service of self-enrichment. ${ }^{[3]}$ An added complicating factor is the critical, nationwide shortage of consultants rendering them highly attractive to the private sector, which, in the case of Netcare private hospitals attached to the Pelonomi and Universitas Academic hospitals, has 90 State specialists 'doubling up'. This is in terms of a long-standing agreement with the province, re-affirmed earlier this year amid much legal wrangling when Dr Benny Malakoane, the Free State MEC, suddenly revoked all RWOPS work during State hours at the height of the national controversy. He capitulated after the Public Servants Association won a court interdict preventing him from enforcing his edict - and senior consultants persuaded him that they had tightened up their RWOPS monitoring.

RWOPS was originally introduced as a skills retention and enhancement tool - both vital outcomes nearly lost in the emotive and clouded debate that erupted earlier this year when cooler heads called for an angry National Minister of Health to 'not throw the baby out with the bathwater'. Prof. Errol Holland, Chairperson of the South African Committee of Medical Deans, and Dean of the Health Science Faculty at Medunsa, said at the time that 'a proper rational, constructive way' to ensure that the system operated optimally was urgently needed to address 'a problem of crisis proportions. Each province seems to have a different approach to RWOPS and a multi-stakeholder interim solution needed thrashing out pending a review of the relevant legislation. One was hoping that with occupation specific dispensation one would remove the need for, particularly senior, staff to go out and supplement their salaries with RWOPS, but it's certainly not abated the problem. Holland described the situation as 'untenable - it doesn't bode well for the profession which has a much bigger mission; getting healthcare on track to serve our country's dire needs, particularly in the under-resourced population. We must keep our crisis of maternal and child mortality in mind'.

\section{Chris Bateman}

chrisb@hmpg.co.za

\footnotetext{
1. Bateman C. RWOPS abuse - Government's had enough. S Afr Med J 2012;102(12):899-901. [http://dx.doi.org/10.7196/ SAMJ.6481]

2. Bateman C. RWOPS abuse could cost, or even ruin, offenders. S Afr Med J 2013;103(8):506-508. [http://dx.doi.org/10.7196/ SAMJ.7235]

3. Bateman C. RWOPS abuse 'eroding ethical standards of juniors'.

S Afr Med J 2013;103(8):505-506. [http://dx.doi.org/10.7196/ SAMJ.7165]
}

S Afr Med J 2013;103(12):888

DOI:10.7196/SAMJ.7693 